\title{
Pelatihan Multimedia Interaktif Bagi Guru Guru SMP Negeri 1 Karangawen Demak
}

\author{
Achmad Buchori, Noviana Dini Rahmawati, Dina Prasetyowati, Ika Menariati, \\ Agus Setiawan \\ Universitas PGRI Semarang \\ buccherypgri@gmail.com
}

Received: $7^{\text {th }}$ May $2020 \mid$ Accepted: $30^{\text {th }}$ November $2020 \mid$ Published: $30^{\text {th }}$ January 2021

Key word:

Interactive

Multimedia;,

Kahoot;

ProProfs;

Prezi; Lectora;

Technological

Innovations

\section{Kata Kunci}

Multimedia

Interaktif;

Kahoot;

ProProfs;

Prezi; Lactora;

Inovasi

Teknologi

\section{Abstract}

One of the technological innovations so that learning becomes conducive, interactive, interesting and can help teachers make evaluations of students to use the Kahoot platform. Kahoots are in the form of game applications, quiz choices, or opinion surveys and public opinions of students or institutional members conducted online through a web browser. The problem with partners is that the teachers of SMP Negeri 1 Karangawen, Demak Regency still need refreshment in making interactive multimedia. The methods applied in this service program are the presentation methods, demonstration methods, and practice methods. The presentation method was applied in the introduction of Kahoot software, ProProfs, Prezi of its usefulness, and its application in making interactive learning media, Demonstration Methods regarding program operationalization and Practice Methods where teachers directly practiced making instructional media in accordance with their respective subjects using Kahoot programs, ProProfs, Lectora, and Prezi.

\section{Abstrak}

Salah satu inovasi teknologi agar pembelajaran menjadi kondusif, interaktif, menarik

serta dapat membantu pengajar membuat evaluasi penilaian terhadap peserta didik adalah menggunakan platform Kahoot. Kahoots berupa aplikasi permainan, quis pilihan ganada, ataupun survey pendapat dan opini publik peserta didik atau anggota institusi yang dilakukan secara online melalui web browser. Permasalahan mitra adalah guru SMP Negeri 1 Karangawen Kabupaten Demak masih membutuhkan penyegaran dalam hal pembuatan multimedia interaktif. Metode yang diterapkan dalam program pengabdian ini, yaitu metode presentasi, metode demonstrasi, dan metode praktik. Metode presentasi diterapkan dalam pengenalan software Kahoot, ProProfs, Prezi kemanfaataannya, dan penerapannya dalam pembuatan media pembelajaran interaktif, Metode Demonstrasi mengenai pengoperasionalisasian program dan Metode Praktik dimana guru-guru mempraktikkan secara langsung pembuatan media pembelajaran sesuai mata pelajaran masing-masing dengan pemanfaatan program Kahoot, ProProfs, Lectora, dan Prezi. 


\section{PENDAHULUAN}

Teknik pengajaran konvensional cenderung membuat pelajaran membosankan karena suasana proses pembelajaran tidak menarik dan cenderung peserta didik sulit untuk fokus pada proses pembelajaran. Proses pembelajaran dan pengajaran yang kondusif, menyenangkan dan tidak membosankan bagi peserta didik di dunia pendidikan dibutuhkan agar maksud dan tujuan pengajaran yang diharapkan dalam proses pembelajaran mudah dicapai (Jaya, 2017). Era Revolusi Industri 4.0 yang tengah melanda segala kehidupan menjadikan perguruan tinggi harus mampu beradaptasi dengan perkembangan teknologi, salah satunya menjadikannya dalam proses pembelajaran yang kondusif dan menyenangkan (Andriani, 2015). Guru, dosen dan Pengembang Teknologi Pembelajaran memiliki peran penting dalam hal mengembangkan inovasi, ide atau gagasan untuk pemanfaatan teknologi dalam pembelajaran. Keuntungan pembelajaran dengan teknologi dapat menciptakan iklim belajar yang efektif bagi peserta didik yang lamban dalam pembelajaran, merangsang peserta didik dalam mengerjakan latihan dan dapat menyesuaikan kecepatan kecepatan belajar dapat sesuai dengan kemampuan peserta didik (Gunawan et al., 2017).
Model pembelajaran adalah suatu perencanaan atau pola pembelajaran yang bertujuan menentukan materi pembelajaran salah satunya termuat dalam program program media komputer, mengingat suatu model berfungsi mengarahkan perencanaan pembelajaran yang membantu peserta didik mencapai berbagai tujuan. Inovasi model pembelajaran dianggap penting untuk meningkatkan pemahaman siswa (Mustami, 2009).

Beberapa software banyak digunakan untuk membantu para guru dalam membuat materi ajar, mengoptimalkan media pembelajaran, membuat quiz, dan mengevaluasi pembelajaran. Prezi merupakan salah satu software berbasis internet yang banyak digunakan guru untuk menyusun presentasi (Hakim Lukman, 2017).

Selain Prezi, beberapa software lain yang sering digunakan untuk pembelajaran adalah Kahoot. Kahoot adalah merupakan salah satu media pembelajaran berbasis teknologi yang dapat meningkatkan minat dan keaktifan siswa. Siswa dapat belajar sambal bermain dan berkompetisi (Jamiludin et al., 2020).

Lectora juga merupakan salah satu software yang dapat digunakan. Lectora inspire didesain khusus bagi pemula 
sehingga keunggulan dari lectora inspire sangat mudah digunakan dalam pembuatan media pembelajaran dan dapat membuat materi uji atau evaluasi (Shalikhah, 2017).

\section{SMP Negeri 1 Karangawen} Kabupaten Demak masih membutuhkan penyegaran dalam hal pembuatan multimedia interaktif. Berdasarkan pelaksanaan observasi yang dilakukan, sekolah tidak memiliki laboratorium pembelajaran yang berbasis IT, sehingga pembelajaran selalu dilaksanakan di kelas. Selain itu, pembelajaran juga masih dominan menggunakan media-media konvensional yaitu papan tulis dan buku, jarang sekali menggunakan media komputer. Terbatasnya penggunaan media pembelajaran oleh guru mengakibatkan model pembelajaran yang diterapkan juga bersifat terbatas pada aktifitas fisik saja, akan sulit sekali untuk merumuskan model pembelajaran yang memadukan segala aspek (Nurseto, 2012).

Lebih lanjut diperoleh informasi bahwa minimnya guru yang memahami penyusunan atau penggunaan media pembelajaran menggunakan komputer. Sementara itu, teknologi komputer dapat menjadi multimedia dalam pembelajaran yang artinya penggunaan aplikasi komputer dapat berfungsi lebih dari sebagai satu media.
Oleh karena itu, tim pengabdian pada masayarakat Universitas PGRI Semarang melakukan komunikasi secara intensif dengan pengelola SMP Negeri 1 Karangawen Demak untuk mendapatkan solusi dari permasalahan tersebut. Komunikasi yang dilakukan menghasilkan suatu keputusan bahwa perlu diadakannya suatu pelatihan dan pendampingan pembuatan multimedia pembelajaran interaktif.

\section{METODE}

Kegiatan pengabdian ini dilaksanakan di SMP Negeri 1 Karangawen Demak dengan alamat Jl. Raya Karangawen No. 105 Lerap, Pundenarum, Kecamatan Karangawen Kabupaten Demak. Kegiatan dalam program PKM ini meliputi pemberian pelatihan kepada guru di sekolah tersebut, serta pembimbingan pembuatan produk hingga produk tersebut selesai dan dapat digunakan seperti yang diharapkan. Kegiatan pertama yang dilakukan adalah observasi lapangan untuk memperoleh data awal tentang sarana dan prasarana pendukung pelatihan atau workshop termasuk waktu yang dapat digunakan untuk pelatihan.

Pelaksanaan kegiatan pelatihan bagi guru-guru ini bertempat di laboratorium SMP Negeri 1 Karangawen dan berlangsung selama 
4 hari yaitu :

1. Pertemuan pertama Rabu, 19 Februari 2020. Materi yang disampaikan pada hari pertama adalah pembuatan email, pengenalan Kahoot dan praktik membuat quiz dengan Kahoot;

2. Pertemuan kedua Rabu, 26 Februari 2020. Pertemuan hari kedua berisi materi tentang pengenalan Prezi serta penggunaannya;

3. Pertemuan ketiga dilaksanakan tanggal 5 Maret 2020 berisi materi tentang pengenalan dan penggunaan ProProfs;

4. Pertemuan keempat dilaksanakan tanggal 12 Maret 2020 dengan materi pengenalan dan penggunaan Lectora dalam pembelajaran.

Ada tiga metode yang diterapkan dalam program pengabdian ini, yaitu metode presentasi, metode demonstrasi, dan metode praktik. Metode presentasi diterapkan dalam pengenalan software Kahoot, ProProfs, Prezi, kemanfaataannya, dan penerapannya dalam pembuatan media pembelajaran interaktif, Metode Demonstrasi mengenai operasi program dan Metode Praktik dimana guru-guru mempraktikkan secara langsung pembuatan media pembelajaran sesuai mata pelajaran masing- masing dengan pemanfaatan program Kahoot, ProProfs, dan Prezi. Adapun langkah yang telah ditempuh dalam kegiatan PKM ini mencakup beberapa tahap berikut ini.

\section{Persiapan}

Tahap persiapan merupakan tahap awal sebelum pelaksanaan PKM. Dalam tahap ini ada beberapa hal yang dilakukan, yakni Koordinasi Internal, dilakukan oleh Tim untuk merencanakan pelaksanaan secara konseptual, operasional, serta job description masing- masing anggota, pembuatan Instrumen PKM, seperti lembar presensi, angket, lembar kerja, persiapan konsumsi, publikasi, lokasi, dokumentasi, dan sebagainya.

\section{Pelaksanaan Pelatihan}

Tahap ini merupakan tahap pelatihan yang diberikan kepada para guru SMP Negeri 1 Karangawen Demak. Pelaksanaan pelatihan ini mencakup
a. Penyajian materi
b. Praktik pembuatan multimedia interaktif berbasis Kahoot, ProProfs, dan Prezi.
c. Penugasan praktik
d. Pendampingan
e. Evaluasi dan Penyempurnaan Karya Media Pembelajaran oleh Tim
f. Refleksi dan penutupan program PKM.

\section{HASIL}

Selama 4 hari pelaksanaan kegiatan, peserta diberikan materi tentang Pembuatan Email, Media Kahoot, Media 
ProProfs, Media Prezi, dan Media Lectora.

Di akhir kegiatan, para guru wajib membuat hasil praktek membuat Quiz dengan Kahoot, membuat tes online dengan ProProfs, membuat presentasi menggunakan Prezi, dan membuat bahan ajar menggunakan Lectora. Kegiatan ini berlangsung lancar dan interaktif. Selama 4 hari melakukan workshop, para peserta terlihat aktif dan antusias dalam mengikuti semua kegiatan dan materi yang diberikan. Hal ini terlihat dari keseriusan para peserta dalam memperhatikan paparan materi dari tim PKM, dan keaktifan peserta dalam bertanya apabila merasa kurang paham dengan materi yang disampaikan.
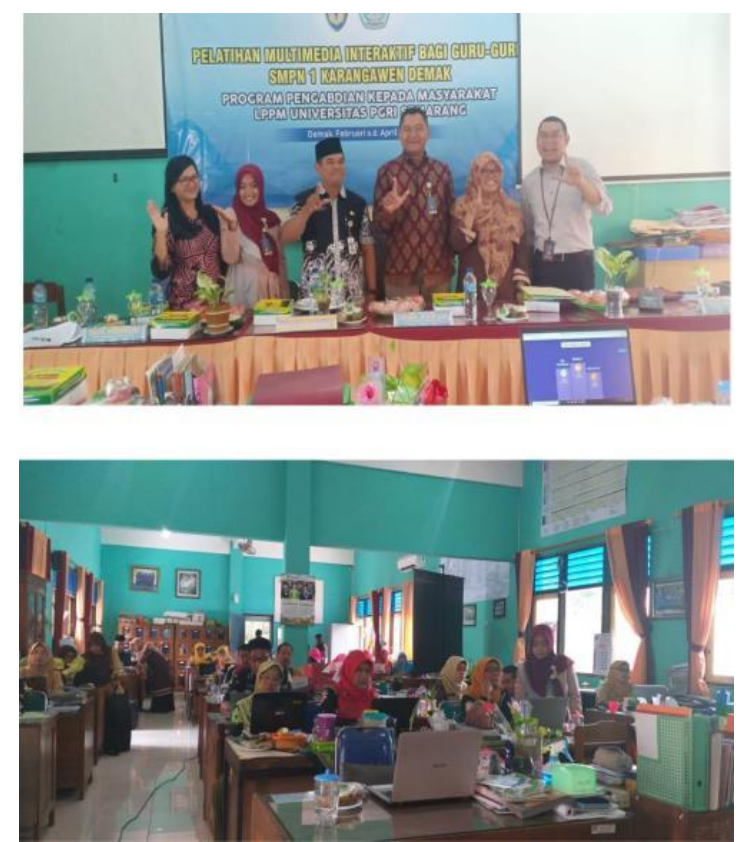

Gambar 1. Pelaksanaan Kegiatan Pelatihan

\section{PEMBAHASAN}

Untuk mengetahui tingkat keberhasilan kegiatan pengabdian ini, dilakukan evaluasi kepada peserta pelatihan
(Aryanti et al., 2015). Evaluasi kepada peserta dilakukan setelah materi ceramah, diskusi dan praktek selesai diberikan. Evaluasi ini untuk mengungkap apakah para guru SMP Negeri 1 Karangawen telah mampu membuat membuat Quiz dengan Kahoot, membuat tes online dengan ProProfs, membuat presentasi menggunakan Prezi, dan membuat bahan ajar menggunakan Lectora.
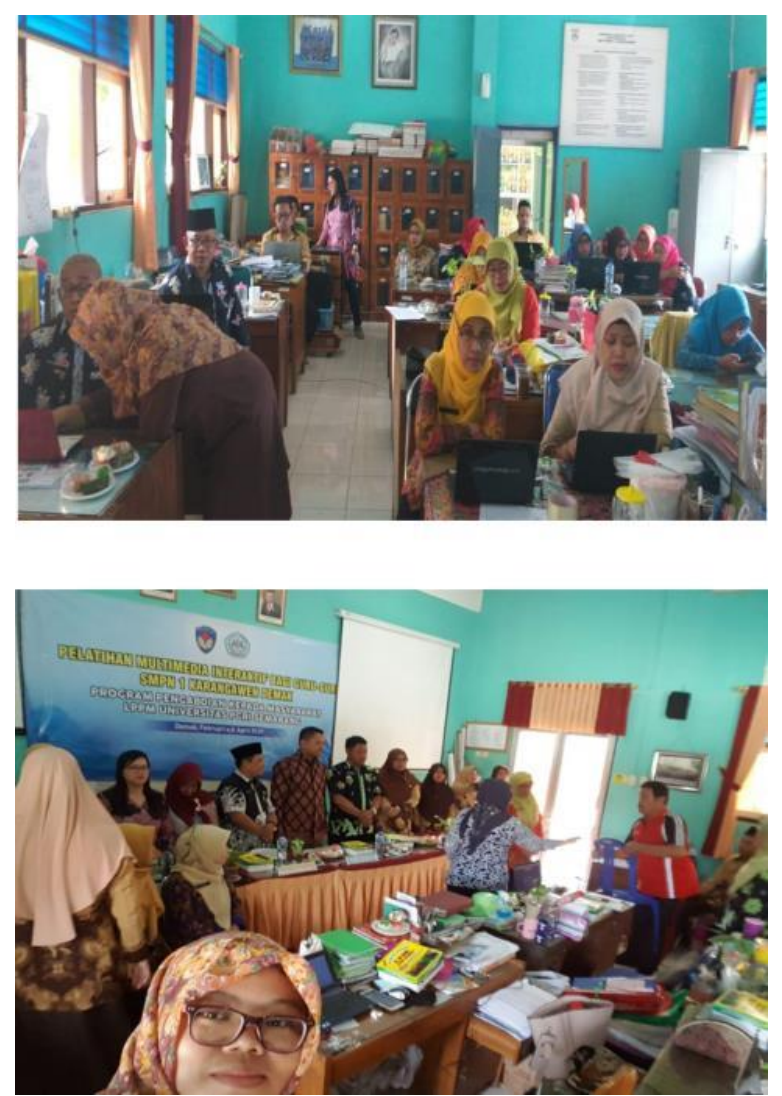

Gambar 2. Pendampingan Unjuk Kerja Peserta Kegiatan

Kendala yang dihadapi oleh para peserta dalam mengikuti pelatihan ini antara lain adalah faktor usia guru yang bervariasi sehingga ada peserta yang dengan mudah memahami materi, tapi sebagian yang lainnya agak lambat dalam memahami 
materi yang dipaparkan. Selain itu, kondisi sarana dan prasarana dari masing- masing sekolah berbeda-beda, sehingga antara satu peserta dengan yang lainnya juga berbeda dalam mempraktikkan media pembelajaran di kelas masing-masing. Kurangnya pengalaman dalam membuat media pembelajaran menyebabkan para peserta terhambat untuk membuat media pembelajaran.

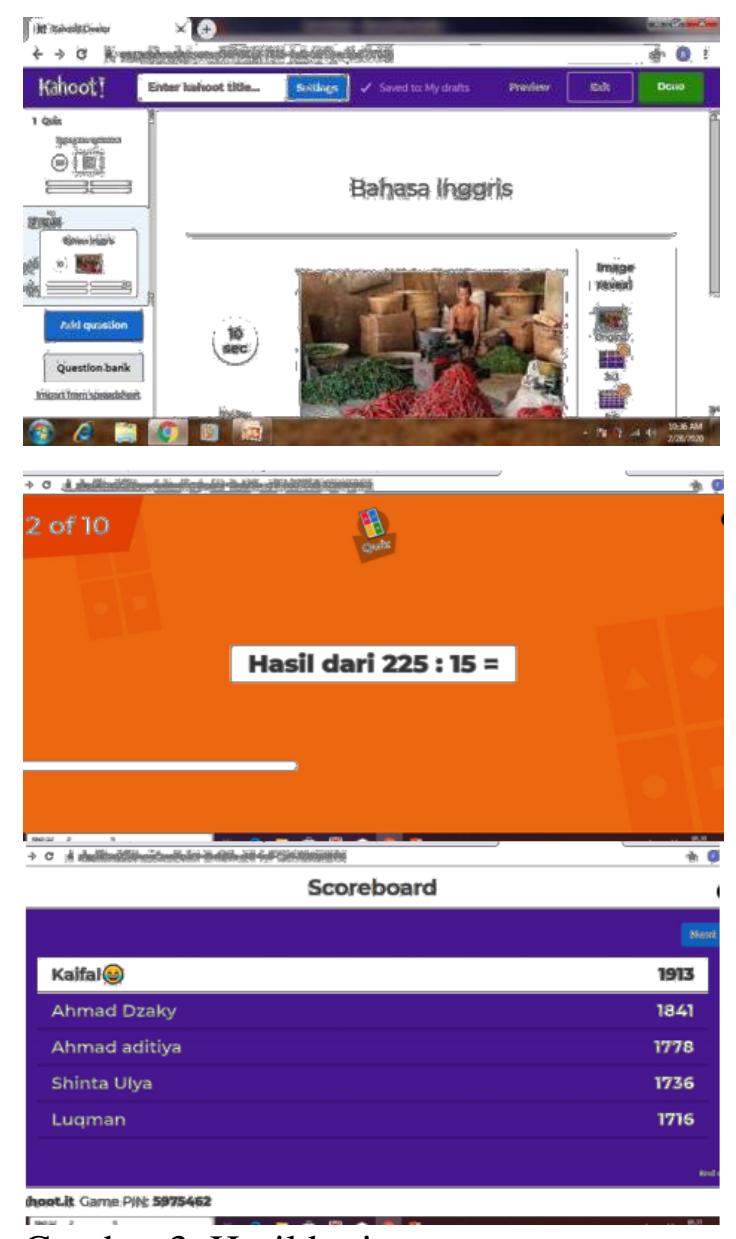

Gambar 3. Hasil kerja peserta

\section{SIMPULAN}

Simpulan yang dapat diambil dari kegiatan PKM ini adalah sebagai berikut.

\section{SMP Negeri 1 Karangawen}

sangat respond dan mendukung seluruh kegiatan Program Kemitraan Masyarakat (PKM) ini terlihat dari para peserta terlihat aktif dan antusias dalam mengikuti semua kegiatan dan materi yang diberikan.

2. Pelatihan pembuatan media interaktif bagi para guru sangat penting karena dapat menunjang karir dalam menghadapi Era Revolusi Industri 4.0.

3. Pendampingan dalam pembuatan media interaktif sangat penting karena proses pembuatan yang semuanya dilakukan secara online terkadang membingungkan bagi para guru.

\section{SARAN}

Saran terhadap program pengabdian ini adalah guru SMP Negeri 1 Karangawen dapat memposisikan media pembelajaran sebagai salah satu komponen penting dari suatu proses pembelajaran. Selain itu, melihat pentingnya materi pelatihan ini, diharapkan pelatihan sejenis dapat dilaksanakan kembali di masa datang.

\section{UCAPAN TERIMA KASIH}

Terimakasih Tim Pengabdi sampaikan kepada Lembaga Penelitian dan Pengabdian kepada Masyarakat Universitas 
PGRI Semarang (LPPM UPGRIS), yang telah memberikan kesempatan kepada Tim melaksanakan kegiatan Pengabdian Kepada Masyarakat. Selanjutnya Tim sampaikan terimakasih kepada Kepala SMP N 01 Karangawen Demak, telah memberikan kesempatan kepada Tim untuk dapat berbagi ilmu; khususnya dalam merancang pembelajaran berbasis digital di era Revolusi Industri 4.0

\section{DAFTAR PUSTAKA}

Andriani, T. (2015). SISTEM

PEMBELAJARAN BERBASIS

TEKNOLOGI INFORMASI DAN

KOMUNIKASI. Sosial Budaya:

Media Komunikasi Ilmu-Ilmu Sosial

dan Budaya, 12(1), 127-150.

Aryanti, T., Supriyono, S., \& Ishaq, M.

(2015). Evaluasi Program Pendidikan

Dan Pelatihan. Jurnal Pendidikan

Nonformal, 10(2), 1-13.

Gunawan, I., Ulfatin, N., Sultoni, S.,

Sunandar, A., Kusumaningrum, D. E.,

\& Triwiyanto, T. (2017).

Pendampingan Penerapan Strategi

Pembelajaran Inovatif dalam

Implementasi Kurikulum 2013.

Abdimas Pedagogi, 1(1), 37-47.

Hakim Lukman, D. (2017). Pelatihan

Pembuatan Bahan Ajar Matematika

Media Prezi. UNES Journal Of

Community Service, 2(2), 157-163.
Jamiludin, J., Darnawati, D., Uke, W. A. S., \& Ayu, A. P. (2020). Pelatihan

Media Kahoot pada Guru dalam

Proses Evaluasi Belajar. Amal Ilmiah :

Jurnal Pengabdian Kepada

Masyarakat, 1(2), 63-67.

Jaya, H. N. (2017). Keterampilan Dasar

Guru untuk Menciptakan Suasana

Belajar yang Menyenangkan. Jurnal

Pendidikan dan Ilmu Pengetahuan, 17(1), 23-35.

http://103.114.35.30/index.php/didakti s/article/view/1555/1275

Mustami, M. K. (2009). Inovasi ModelModel Pembelajaran Bidang Sains Untuk Meningkatkan Hasil Belajar Mahasiswa. Lentera Pendidikan : Jurnal Ilmu Tarbiyah dan Keguruan, 12(2), 125-137. https://doi.org/10.24252/lp.2009v12n2 a1

Nurseto, T. (2012). Membuat Media Pembelajaran yang Menarik. Jurnal Ekonomi dan Pendidikan, 8(1), 19-35. https://doi.org/10.21831/jep.v8i1.706

Shalikhah, N. D. (2017). Media

Pembelajaran Interaktif Lectora Inspire sebagai Inovasi Pembelajaran. Warta LPM, 20(1), 9-16. https://doi.org/10.23917/warta.v19i3.2 842 